\title{
Orthopedic rehabilitation of elderly cancer patients as a technology of longevity
}

\author{
Vera V. Karaseva ${ }^{1 *}$, Tatyana M. Elovikova ${ }^{2}$, Sergey E. Zholudev ${ }^{1}$, Anatoly S. Koshcheev ${ }^{3}$, \\ and Artem S. Prihodkin ${ }^{1}$ \\ ${ }^{1}$ Ural State Medical University, Department of orthopedic dentistry and general dentistry, 620028, \\ Repin str., 3, Yekaterinburg, Russian Federation \\ ${ }^{2}$ Ural State Medical University, Department of therapeutic and propaedeutic of dental diseases, \\ 620028, Repin str., 3, Yekaterinburg, Russian Federation \\ ${ }^{3}$ Ural Federal University, Department of Simulation of controlled systems, 620028, Repin str., 3, \\ Yekaterinburg, Russian Federation
}

\begin{abstract}
Defects after resection of the upper jaw lead to communication of the oral cavity with the nasal cavity, chewing disorders, aesthetic problems and other functional disorders. The aim of the study is to assess the dental status and quality of life of elderly patients with upper jaw defects, as a technology of longevity, at the stage of orthopedic rehabilitation. 24 patients were examined, divided into two groups of 12 people aged from 58 to 74 years. The main group - patients after resection of the upper jaw for malignant neoplasms. Buccal epithelial cells and quality of life of patients were studied before and after prosthetics. After orthopedic rehabilitation, there is a tendency to restore the barrier properties of the oral mucosa and improve the quality of life of patients. Orthopedic rehabilitation of patients with upper jaw defects using obturator prostheses is an appropriate and non-invasive method of treatment for the elderly.
\end{abstract}

\section{Introduction}

Malignant neoplasms of organs and tissues in the head and neck region occupy the sixth place in the overall world structure of cancer incidence and are among the ten most common tumor localities, meanwhile the proportion of head and neck cancer is $2.8 \%$ [117]. In Russia, the prevalence rate of oral malignancies is 2.02 , and in the Sverdlovsk region it is slightly higher -2.05 per 100 thousand population [16].

Treatment of cancer patients is complex, including surgical excision of the tumor, chemotherapy and radiation therapy. The frequency and severity of complications depends on many factors related to both radiation therapy and individual characteristics of the patient [1,4,6,10-13,17-21].

Operations for neoplasms of the maxillofacial area often lead to aesthetic disorders, the formation of extensive defects, and in the presence of communication between the oral cavity and the nasal cavity and functional disorders - speech distortion, respiratory

\footnotetext{
*Corresponding author: vevaska500@mail.ru
} 
changes, chewing and swallowing disorders $[20,22]$. These changes lead to disability and social maladaptation of patients. Surgical closure of postoperative defects is Therefore, more often the restoration of maxillofacial defects is performed by orthopedic methods. Orthopedic rehabilitation of cancer patients has its own features and difficulties. The long duration of treatment, patients' anxiety about the outcome of diseases, the possibility of maintaining social status, as well as postoperative functional disorders lead to a decrease in the quality of life of these patients [17,18].

It should be noted that an important role in the implementation of protective mechanisms belongs to the epithelium of the oral mucosa. These mechanisms include high enzymatic activity, the intensity of metabolic processes and their ability to quickly rearrange $[1,2,7,23]$. The frequency of oral mucosal pathology in cancer patients is very high, even in the conditions of standard chemotherapy, it is determined within a fairly wide range $[1,2,4,6,7,19]$. Therefore, the study of the morphofunctional state of buccal epithelial cells as a factor of colonization resistance of anti-infectious protection of the oral cavity in patients with oncological pathology at the stages of orthopedic rehabilitation is relevant $[2,7,23]$. All of the above points to the feasibility of evaluating the effectiveness of orthopedic rehabilitation of patients with upper jaw defects using obturators to improve the quality and increase their life expectancy.

The purpose of the study is to analyze the assessment of the dental status and quality of life of elderly patients with upper jaw defects and edentulous spaces, as a technology of longevity, at the stage of orthopedic rehabilitation.

\section{Materials and Methods}

The study was performed at the Department of orthopedic dentistry and general practice dentistry, and the Department of therapeutic and preclinical dentistry of the Ural state medical University (USMU) of the Ministry of healthcare of the Russian Federation; mathematical development of the results of the study carried out at the Department of Simulation of controlled systems of the Ural Federal University named after first President of Russia B.N. Yeltsin (UrFU).

We examined 24 patients divided into two groups of 12 people aged from 58 to 74 years (average age $65.5 \pm 4.5$ years). The main group (1) - patients after resection of the upper jaw for malignant neoplasms. The patients were treated in the radiological department of the Sverdlovsk regional oncology dispensary. The average duration of the disease was 1.5-3 years. Comparison group (2) - patients who applied to the USMU clinic for dental prosthetics, who do not have a history of oncological pathology with a predominant loss of teeth in the upper jaw [4,23].

Clinical dental examination included: collection and analysis of complaints, anamnesis, examination of oral cavity: oral hygiene level, DMFT index, assessment of periodontal tissues and mucous membrane of the mouth, Simplified Oral Hygiene Index (OHI-S, Green I.G. and Vermillion I.R., 1964), papillary bleeding index (PBI, Muhlemann H.R. and Cowell I., 1975), to the extent of inflammation of periodontal tissues used the Periodontal Index (Russell index, 1956), condition of the salivary glands (sialometry), filled card of dental examination [1,4-6,21].

The main complaints of patients of the first group: impaired appearance, slurred speech (open nasal) and difficult eating, associated with the presence of postoperative defect of the jaws. In a survey of patients, it was found that from 1 to 3 years ago they were operated on for invasive squamous cell cancer with resection of jaw fragments. There were no plans to close defects surgically for health reasons and due to the age of the patients.

Qualitative analysis of saliva was performed in patients of both groups according to the following parameters: transparency, color, inclusions, viscosity, acid-base balance $(\mathrm{pH})$. 
The viscosity of saliva was determined using a pipette, slide glass, metal spatula and ruler, considering that saliva normally stretches no more than $5 \mathrm{~mm}[1,19,21,24,25]$.

Saliva $\mathrm{pH}$ was measured using universal indicator test strips "Special Test Paper" ( $\mathrm{pH}$ 4.5-9.0). The test strip was immersed in a "saliva lake" in the sublingual area for 3 seconds. The result was compared with a control color scale. Normally, the $\mathrm{pH}$ of saliva is 6.4-7.8 units $[1,19,21,24,25]$.

The material for the study of the morphofunctional state of buccal epithelial cells was smears from the oral mucosa. The smears were fixed, stained with methylene blue and examined using a microscope (binocular type MBS "MC 20") at magnification $=700.100$ squamous epithelial cells were analyzed in each smear, taking into account the degree of destruction $[2,7,23]$. The degree of destruction of epithelial cells was assessed taking into account a number of morphological criteria according to the method described by O.P. Bochkareva et al.:

0 class of destruction - cells with a normal structure of the nucleus and cytoplasm;

1 st class of destruction - cells with a normal nucleus structure and partial (no more than 1/2) destruction of the cytoplasm;

2nd class of destruction - cells with partial destructive damage to the nucleus and significant (more than 1/2), but not complete destruction of the cytoplasm;

3 rd class of destruction - cells with complete destruction of the cytoplasm and severe (not complete) destruction of the nucleus;

4th class of destruction - cells with complete destruction of the nucleus and cytoplasm $[2,26]$.

Evaluation of the results of prosthetics and quality of life of maxillofacial patients before and after orthopedic rehabilitation was carried out using a questionnaire developed by us, which includes questions that allow us to evaluate on a ten-point scale parameters: pain, numbness, changes in the function of swallowing, chewing, speech, salivation, taste, social activity, mood, appearance. Quality of life scores are classified as acceptable (score 6.0), good (score 8.0), and very good (score 10.0).

Mathematical processing of research results was performed on a personal computer using Microsoft Excel 2007, the reliability of differences was evaluated by the Student's tdistribution using the Statistica 6.0 software package; $\mathrm{M} \pm \mathrm{m}$ defines the confidence interval for mathematical expectation, where $M$ is the sample average, $m=z \cdot \sigma_{x} / \sqrt{ } n, n$ is the sample size, $\sigma_{\mathrm{x}}$ is the sample mean square deviation, the number $\mathrm{z}$ satisfies the condition $\mathrm{F}(\mathrm{z})=0.5-\mathrm{p} / 2(\mathrm{~F}(\mathrm{z})$ is the Laplace function, for $\mathrm{p} \leq 0.05$, you can take $\mathrm{z}=2)$. To determine the effectiveness of orthopedic rehabilitation of patients of the main group and the comparison group, we used the problem of evaluating the hypothesis of equality of mathematical expectations of two independent normally distributed random variables with a one-sided critical area based on the Student's t-distribution.

\section{Results and Discussion}

During the initial examination, partial loss of teeth and attrition was determined in all patients, $(\mathrm{DMFT}=21.75 \pm 3.5$ in the main group and $19.5 \pm 3.75$ in the comparison group, in both groups, the component "M" - missing prevails). OHI-S values were high: $2.85 \pm$ 0.35 units. There is a significant amount of plaque in the root area and in the interdental spaces, supragingival and subgingival dental calculus (dark gray, dense, in moderate amounts, mainly in the area of the contact and lingual surfaces of the lower incisors).

Periodontal pathologies were observed in all patients in the main group and the comparison group. PBI was mainly of the 2 nd degree - bleeding occurs within 30 seconds after the study. Russell index $-3.75 \pm 0.5$ and $3.95 \pm 0.75$, respectively. 
Based on clinical evidence, a diagnosis of moderate periodontitis and initial stage xerostomia was made. The mucous membrane of the lips, cheeks, hard and soft palate, tongue, and floor of the mouth is pale pink, thinned, and macerated. All patients in the main group revealed total through defects of the upper jaw, postoperative scars after resection of jaw fragments.

In the study of the acid-base state of saliva in patients of the main group (1), the $\mathrm{pH}$ values were $6.25 \pm 0.5$ (slightly acidic), in patients of comparison group (2) - the $\mathrm{pH}$ values were $6.75 \pm 0.15$.

Qualitative analysis of saliva showed that the saliva is colorless, without impurities, the viscosity is slightly increased - the length of the "threads" is more than $6 \mathrm{~mm}$.

After orthopedic treatment of patients, the saliva viscosity decreased, the length of the "threads" $-4.5 \pm 1.0 \mathrm{~mm}$.

The results of the primary cytological study showed that the number of buccal epithelial cells with class 0 destruction in patients of the main group was $51.4 \pm 3.25 \%$, in the comparison group $-69.5 \pm 5.5 \%$, after $-55.9 \pm 3.45 \%$ and $75.5 \pm 6.5 \%$, respectively. The number of buccal epithelial cells with class 1 destruction in patients of the main group was $15.75 \pm 3.25 \%$, in the comparison group $-20.95 \pm 5.75 \%$, after $-13.50 \pm 4.5 \%$ and $22.35 \pm$ $3.5 \%$, respectively (table 1 ). The number of buccal epithelial cells with class 2 destruction in patients of the main group was $16.5 \pm 2.75 \%$, in the comparison group $-6.90 \pm 1.25 \%$, after $-14.5 \pm 1.5 \%$ and $2.15 \pm 0.8 \%$, respectively (table 1 ).

Table 1. Buccal epithelial cell destruction class in the main group of patients and the comparison group "before" and "after" orthopedic rehabilitation (\%; $\mathrm{M} \pm \mathrm{m})$

\begin{tabular}{|l|c|c|c|c|c|}
\hline \multirow{2}{*}{ Group of patients } & \multicolumn{5}{|c|}{ Class of epithelial cell destruction } \\
\cline { 2 - 6 } & 0 class & 1 class & 2 class & 3 class & 4 class \\
\hline Main group' & $51,4 \pm 3,25^{*}$ & $15,75 \pm 3,25^{*}$ & $16,5 \pm 2,75^{*}$ & $10,0 \pm 2,50^{*}$ & $6,25 \pm 0,0^{*}$ \\
\hline Main group" & $55,9 \pm 3,45^{* *}$ & $13,50 \pm 4,5^{* *}$ & $14,5 \pm 1,5^{* *}$ & $13,35 \pm 1,05^{* *}$ & $2,75 \pm 0,5^{* *}$ \\
\hline Comparison group' & $69,5 \pm 5,5$ & $20,95 \pm 5,75$ & $6,90 \pm 1,25$ & $2,65 \pm 0,7$ & $0,0 \pm 0,0$ \\
\hline Comparison group" & $75,5 \pm 6,5$ & $22,35 \pm 3,5$ & $2,15 \pm 0,8$ & $0,0 \pm 0,0$ & $0,0 \pm 0,0$ \\
\hline
\end{tabular}

*-significant differences between groups of patients before orthopedic rehabilitation $(\mathrm{p} \leq 0,05)$

$* *$-significant differences between groups of patients after orthopedic rehabilitation $(p \leq 0,05)$

' - before orthopedic rehabilitation

" - after orthopedic rehabilitation

The number of buccal epithelial cells with class 3 destruction in patients of the main group was $10.0 \pm 2.50 \%$, in the comparison group $-2.65 \pm 0.7 \%$, after $-13.35 \pm 1.05 \%$ and $0.0 \pm 0.0 \%$, respectively. The number of buccal epithelial cells with class 4 destruction in patients of the main group was $6.25 \pm 0.0 \%$, in the comparison group $-2.75 \pm 0.5 \%$, after - buccal epithelial cells of class 4 were not detected.

Thus, after orthopedic treatment, patients showed a decrease in the number of buccal epithelial cells with a high degree of destruction (3rd, 4th classes) and an increase in the number of cells with a low degree of destruction (0, 1, 2 classes) (Fig. 1).
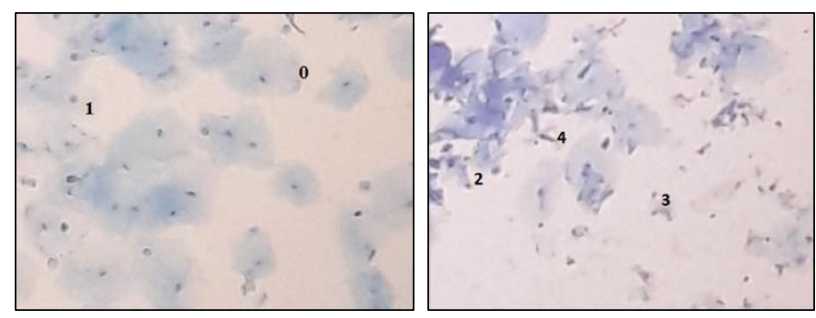

Fig. 1. Buccal epithelial cells, main group, color methylene blue, magnification $\times 700$ 
This indicates a tendency to eliminate violations of the normal course of the process of maturation and differentiation of the epithelium of the oral mucosa, and restore the barrier properties of the buccal epithelium [2].

As an illustration, we present a clinical case of patient K., 66 years old (Fig. 2).
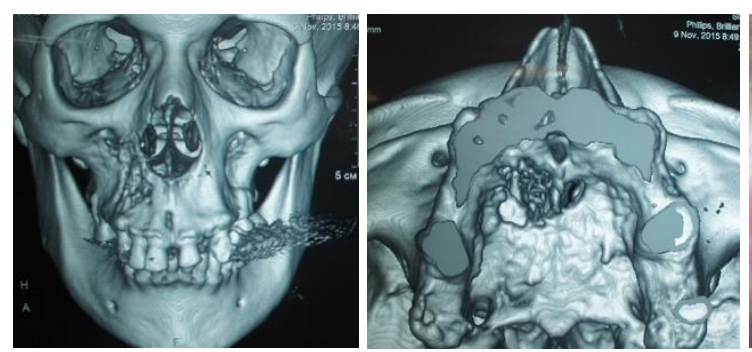

a

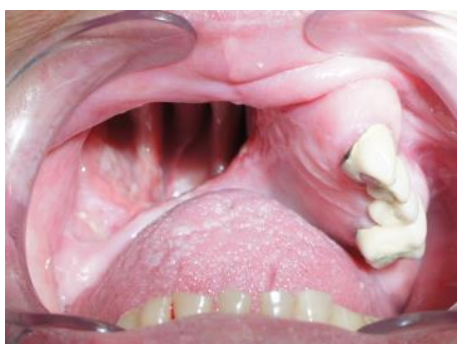

b

Fig. 2. Patient K., 66 years old: a) CT scan before surgery; b) clinical picture (at the time of treatment)

An external examination of patient K., 66 years old, revealed: facial asymmetry on the right, cheek depression, scarring of the upper lip, displacement of the right corner of the mouth up. On the upper jaw on the right, a postoperative total defect of an oval shape, measuring $6 \times 5 \mathrm{~cm}$, communicating with the nasal cavity and maxillary sinus; a defect of the dentition (Kennedy class II). On the preserved fragment of the alveolar ridge on the left - a metal-ceramic dental bridge, abutment teeth 2.3 and 2.6 in insufficient condition. The mucous membrane of the lips, cheeks, hard and soft palate is hyperemic, dry. In the anterior part of the hard palate, parallel to the edge of the defect, a drug-associated osteonecrosis of $1.5 \mathrm{~cm}$ was found. The interdental gingiva was smoothed, marginal gingiva and alveolar mucosa (fragmentary) in the area of preserved teeth are hyperemic and edematous. Solid dental calculuses were found in moderate amounts - the supragingival dental calculus covers from $1 / 3$ to $2 / 3$ of the surface of the teeth, there are individual particles of subgingival dental calculus.

It was planned to manufacture a resection partial removable obturator prosthesis for the upper jaw with telescopic fixation. Telescopic crowns provide good retention of prostheses, even with a large mass and with a minimum number of abutment teeth. Cast metal frame inside the prosthetic base reduces the risk of breakage of the prosthesis, making it more durable. For better stabilization of the prostheses during the function, resection prostheses are made with the obturator part, which replaces the defect. Since the volume of restored tissues is very large, the prostheses are massive. To reduce the weight of the prosthesis it is made hollow (Fig. 3).

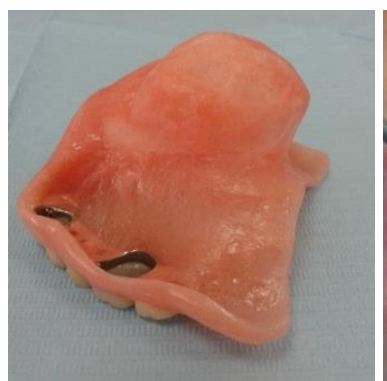

a

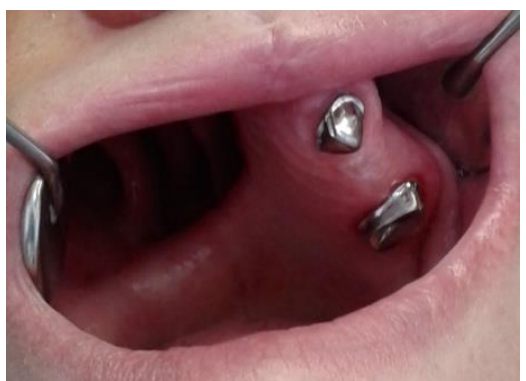

b

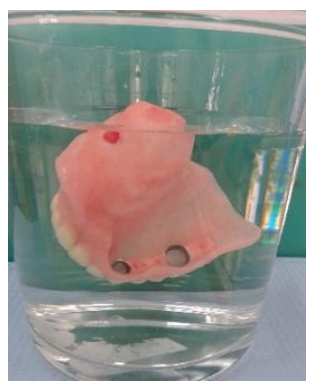

c

Fig. 3. Patient K., 66 years old: a) resection obturator prosthesis, b) fixing of internal telescopic crowns on teeth 2.3 and 2.6 in the oral cavity, c) test for the buoyancy of a hollow prosthesis 
Telescopic crowns are tightly fixed on the teeth, transmit chewing pressure through the periodontal, helping to reduce the load on the denture-bearing area and prevents the displacement of the prosthesis in the defect. A special advantage of prostheses with such fixation is their high aesthetics - the visible absence of supporting elements in the form of metal crowns and clasps (Fig. 4).

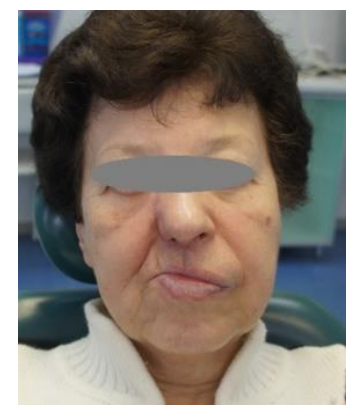

a

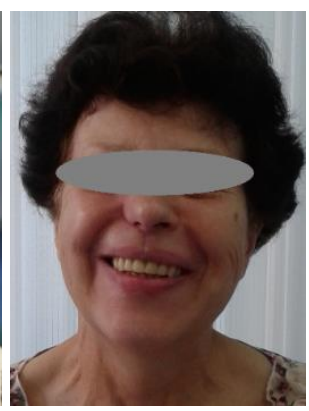

b

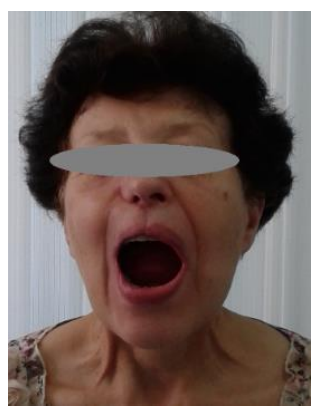

C

Fig. 4. Patient K., 66 years old: a) appearance at the time of treatment, b) appearance after applying the prosthesis, c) test for fixation of the prosthesis (wide opening of the mouth)

The patient quickly adapted to the use of the prosthesis, notes its good fixation and absence of displacement when opening the mouth wide. The basis of the prosthesis fits snugly to the denture-bearing area, well obturates the defect and food does not flow under the prosthesis. As a result of the treatment, breathing, speech, chewing functions were restored, appearance and psychoemotional state improved. After the treatment, the patient began to lead an active lifestyle: she takes her grandchildren to theaters and museums, and even learned to communicate with friends on the Internet.

The results of the survey of patients in the main and comparison groups (evaluation of quality of life before and after orthopedic rehabilitation), are shown in the diagram (Fig. 5).

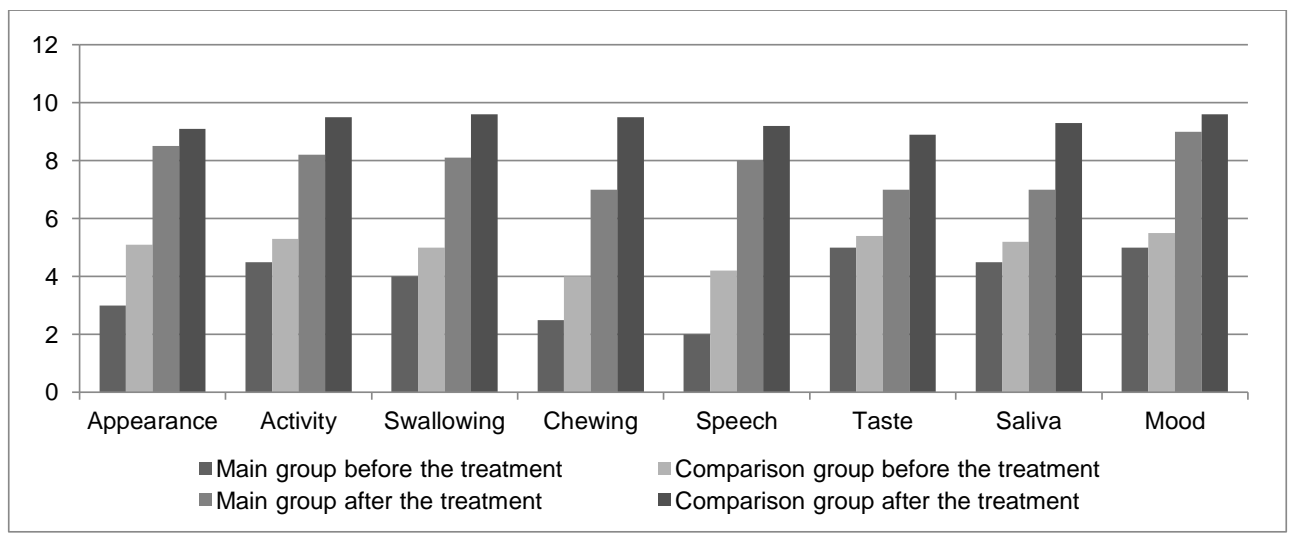

Fig. 5. Results of the survey of patients of the main and comparison groups - assessment of prosthetics and quality of life before and after orthopedic rehabilitation (on a ten-point scale)

Analysis of the results showed that after the operation, patients in the main group experienced discomfort due to poor appearance $-3.0 \pm 0.35$ points, incomplete chewing $2.5 \pm 0.25$ points and slurred speech $-2.02 \pm 0.25$ points. The respondents rated the ability to swallow slightly higher $-4.0 \pm 0.25$ points, activity $-5.05 \pm 0.35$ points and "saliva state" $-5.15 \pm 0.3$ points. In the comparison group, the quality of life indicators were relatively higher, but did not exceed the mark of 6 points. 
All the parameters studied after orthopedic rehabilitation showed positive dynamics. Immediately after applying the prostheses, patients in the main group noted satisfaction with their appearance, smiles $-8.15 \pm 0.25$ points, and especially with the ability to speak (there is no open nasal voice) $-8.15 \pm 0.35$ points. Already in the process of using obturators, patients rated the ability to chew $-7.05 \pm 0.15$ points, swallowing $-8.18 \pm 0.15$ points, activity $-8.08 \pm 0.25$ points and "saliva state" $-7.0 \pm 0.19$ points. The improvement in the quality of life of cancer patients is also evidenced by the dynamics of parameter that characterize mood, which increased from 5.0 points to 9.0. points. At the significance level of $\mathrm{p} \leq 0.05$, a positive change in values was found for all the above parameters compared to the initial data, which reliably confirms the effectiveness of orthopedic rehabilitation.

\section{Conclusion}

Elimination of the upper jaw defect using an obturator prosthesis is an appropriate and noninvasive method of treatment, an important component of orthopedic rehabilitation of elderly cancer patients as a technology of longevity. The advantage of the obturator is the improvement of the appearance of the patient's face, since it provides physiological support for the tissues. In addition, it is still possible to detect tumor recurrence early by examining the postoperative defect, if necessary. Restoring functions such as chewing, breathing, and articulate speech significantly improves the quality of life of elderly patients.

The developed questionnaire can be used for individual monitoring of the quality of life of cancer patients at the stages of orthopedic rehabilitation, as well as evaluating the effectiveness of treatment.

The study of the morphofunctional state of buccal epithelial cells at the stages of orthopedic rehabilitation showed a decrease in destructive changes in these cells, which is a marker for the restoration of barrier properties of the oral mucosa.

\section{References}

1. A.D. Basargina, V.V. Karaseva, T.M. Elovikova, Current issues of modern medicine and healthcare, 37-43 (2017)

2. O.P. Bochkareva, E.P. Krasnozhenov, V.E. Goldberg, N.O. Popova, L.R. Mustafina, Siberian Journal of Oncology, 3, 57-60 (2013)

3. N.G. Vinogradova, M.P. Kharitonova, K.V. Lvov, Ural Medical Journal, 159 (4), 38-48 (2018)

4. T.M. Elovikova, V.V. Karaseva, E.Y. Ermishina, M.E. Shimova, Y.S. Skurihina, Actual Problems in Dentistry, 15 (3), 28-33 (2019)

5. T.M. Elovikova, V.V. Karaseva, V.S. Molvinskikh, Y.S. Skurikhina, A.S. Koshcheev, Actual Problems in Dentistry, 15 (4), 44-49 (2019)

6. V.V. Karaseva, T.M. Elovikova, Dental implantology and surgery, 29 (4), 18-22 (2017)

7. M.A. Lekomtseva, T.M. Elovikova, V.V. Karaseva, Current issues of modern medicine and healthcare, 1129-1133 (2019)

8. E.M. Spevak, A.N. Tsymbal, Kazan medical journal, 98 (1), 91-95 (2017)

9. K. Fleisher, R. Kontio, S. Otto, Antiresorptive drug-related osteonecrosis of the jaw (ARONJ) - a Guide to Research, 177 (2016)

10. A.A. Khan, A. Morrison, D.A. Hanley, D. Felsenberg et al., J Bone Miner Res, 30 (1), 3-23 (2015)

11. T. Mücke, J. Koschinski, H. Deppe, S. Wagenpfeil, C. Pautke, D.A. Mitchell, K.D. Wolff, F. Hölzle, J Cancer Res Clin Oncol, 137 (5), 907-913 (2011) 
12. S. Otto, S. Baumann, M. Ehrenfeld, C. Pautke, J Craniomaxillofac Surg, 41 (7), 694$698(2013)$

13. V. Rollason, A. Laverrière, L.C. MacDonald, T. Walsh, M.R. Tramèr, N.B. VogtFerrier, Cochrane Database Syst. Rev, 30 (2016)

14. S.L. Ruggiero, T.B. Dodson, J.E. Fantasia, R.H.B. Goodday, T. Aghaloo, B. Mehrotra, F. O'Ryan, J Oral Maxillofac Surg, 72 (10), 1938-1956 (2014)

15. S.V. Sirak, A.A. Sletov, R.A. Mozheyko, M.V. Kirpichnikov, A.V. Zhidovinov, E.N. Yarygina, International Journal of Advanced Biotechnology and Research, 8 (2), 526-532 (2017)

16. A.D. Kaprin, V.V. Starinsky, G.V. Petrov, Malignant neoplasms in Russia in 2017 (morbidity and mortality), 250 (2018)

17. M.A. Marwa, K. Nadia, N.A. Mohammed, Head \& Face Medicine, 14 (2), 9 (2018)

18. V.V. Karaseva, Vyatka medical Bulletin, 60 (4), 81-85 (2018)

19. T.M. Elovikova, V.V. Karaseva, M.A. Lekomtseva, M.R. Ulybin, Materials of the International Congress «Dentistry of the Greater Urals», 42-45 (2020)

20. N.B. Astashina, Comprehensive treatment and rehabilitation of patients with acquired jaw defects. Experimental and clinical research, 367 (2009)

21. T.M. Elovikova, V.V. Karaseva, A.S. Koscheev, A.S. Prihodkin, Materials of the International Congress «Dentistry of the Greater Urals», 39-41 (2020)

22. V.V. Karaseva, Actual Problems in Dentistry, 12 (1), 70-76 (2016)

23. E.S. Strokina, S.N. Tantsyreva, E.J. Kostina, T.M. Elovikova, Current issues of modern medicine and healthcare, 317-321 (2018)

24. T.M. Elovikova, S.S. Grigoriev, Sialology in therapeutic dentistry, 192 (2018)

25. T.M. Elovikova, S.S. Grigoriev, Saliva as a biological fluid and its role in oral health, $136(2018)$

26. S.S. Grigorev, D.S. Zholudev, Fundamental research, 1, 488-491 (2015) 